\title{
Retromer: A Master Conductor of Endosome Sorting
}

\author{
Christopher Burd ${ }^{1}$ and Peter J. Cullen ${ }^{2}$ \\ ${ }^{1}$ Department of Cell Biology, Yale School of Medicine, New Haven, Connecticut 06520 \\ ${ }^{2}$ Elizabeth Blackwell Institute for Health Research, Henry Wellcome Integrated Signaling Laboratories, \\ School of Biochemistry, University of Bristol, Bristol BS8 1TD, United Kingdom \\ Correspondence: christopher.burd@yale.edu; pete.cullen@bristol.ac.uk
}

\begin{abstract}
The endosomal network comprises an interconnected network of membranous compartments whose primary function is to receive, dissociate, and sort cargo that originates from the plasma membrane and the biosynthetic pathway. A major challenge in cell biology is to achieve a thorough molecular description of how this network operates, and in so doing, how defects contribute to the etiology and pathology of human disease. We discuss the increasing body of evidence that implicates an ancient evolutionary conserved complex, termed "retromer," as a master conductor in the complex orchestration of multiple cargo-sorting events within the endosomal network.
\end{abstract}

$\mathrm{O}_{s}^{n}$ entering the endosomal network, integral membrane protein cargoes have two fates: either they are sorted from the limiting endosomal membrane into intraluminal vesicles for delivery into the lysosomal degradative pathway (Fig. 1), or they are exported from the endosome via transport carriers that bud from the endosome membrane into the cytoplasm. The endosome export pathways ultimately deliver cargo to the trans-Golgi network (TGN) via retrograde pathways, or to the plasma membrane via recycling pathways (Huotari and $\mathrm{Hel}-$ enius 2011). The principal cargoes of the retrograde pathways are sorting receptors, SNAREs, and other molecules whose functions depend on continual retrieval from the endosomal system back to the biosynthetic pathway (Bonifacino and Rojas 2006; Johannes and Popoff 2008;
Burd 2011). Plasma membrane recycling cargoes are especially diverse in structure, as they include numerous nutrient transporters, mitogenic signaling receptors, and cell adhesion receptors (Maxfield and McGraw 2004; Hsu et al. 2012). Although much has been learned regarding signals and sorting mechanisms that confer sorting into the degradative pathway, these aspects of endosome export pathways are poorly understood. There are therefore significant gaps in our understanding of how the endosomal system is integrated with cell physiology and the development of multicellular organisms, and how deficiencies in endosomal sorting contribute to human disease. Here, rather than give a broad overview of the field (we refer the interested reader to many excellent recent reviews: Grant and Donaldson 2009; Henne et al. 2011;

Editors: Sandra L. Schmid, Alexander Sorkin, and Marino Zerial

Additional Perspectives on Endocytosis available at www.cshperspectives.org

Copyright (C) 2014 Cold Spring Harbor Laboratory Press; all rights reserved; doi: 10.1101/cshperspect.a016774

Cite this article as Cold Spring Harb Perspect Biol 2014;6:a016774 
C. Burd and P.J. Cullen

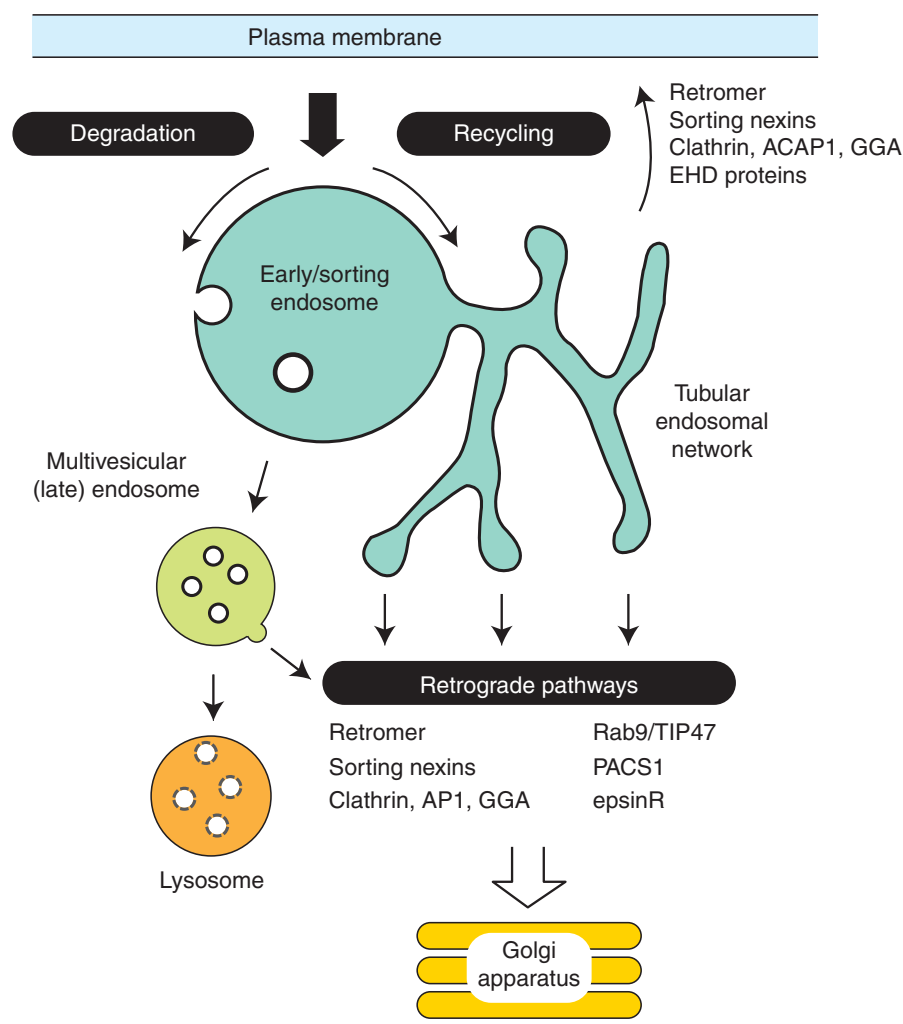

Figure 1. Overview of endosomal sorting pathways. Cargo in the endosome is sorted either into the degradative pathway, leading to its eventual delivery to the lysosome, or into an export pathway that returns it to another organelle for reuse. Recycling export pathways deliver cargo to the plasma membrane, and retrograde export pathways return cargo to the trans-Golgi network. Sorting devices that act in each of these export pathways are listed. Transport carriers of the export pathways bud from the tubular endosomal network, whereas sorting into the lysosomal degradation pathway results in packaging of cargo into vesicles that bud into the lumen of multivesicular endosomes.

Huotari and Helenius 2011; Johannes and Wunder 2011; Hsu et al. 2012), we discuss the role of an evolutionary conserved complex, termed "retromer," that plays a key role in exporting cargo from the endosomal system and is increasingly implicated in many other facets of endosome function.

\section{CARGO EXPORT FROM THE ENDOSOME}

Early studies of endocytosis and lysosomal turnover indicated that the turnover rates for cellsurface receptors and their ligands vary substantially, with that of transmembrane receptors being relatively long-lived, and ligands shortlived. This led to the discovery of plasma mem- brane recycling pathways, whereby internalized receptor-ligand complexes dissociate in the acidic lumen of the endosome and the receptor then exits the endosome with the bulk flow of membrane lipids that are returned to the plasma membrane (Maxfield and McGraw 2004; Hsu et al. 2012). For the plasma membrane recycling of the transferrin receptor (TfnR), one of the most intensively investigated recycling cargoes, initial ideas evoked a sorting signal-independent model in which iterative formation of an extensive network of endosomal tubules ensured that bulk membrane flow occurred through exit from the endocytic network (Mayor et al. 1993). Central to this proposal was the geometric consideration that the relatively large 
ratio of membrane surface area-to-luminal volume of the tubular endosomal network (TEN), when compared with the vacuolar domain of the endosome, effectively serves to segregate integral membrane proteins from luminal content by default (Maxfield and McGraw 2004). It is now clear, however, that the majority of endocytic recycling is mediated in a signal-dependent manner through the engagement of specific sorting signals by a variety of sorting devices (Hsu et al. 2012). Signal-mediated sorting ensures robust endosome function and allows for detailed regulation in response to changes in the cellular environment.

Endosomal cargo export pathways originate from multiple, functionally distinct gateways along the entire endosome maturation pathway. Plasma membrane recycling is mediated by clathrin-containing coat complexes, including clathrin-ACAP1 (that recognizes LF, RF, $\mathrm{KR}$, and PLSLL sequences) and clathrin-GGA3 (Prorich motifs), that recognize cell adhesion receptors and nutrient transporters (Dai et al. 2004; Li et al. 2007; Parachoniak et al. 2011). Similarly, other, less well described sorting factors such as sorting nexin-17 (SNX17) (NPxY, NxxY, and NxxF sequences), EHD proteins (NPF motif), and sorting nexin-27 (SNX27) (PDZ ligands) also contribute to plasma membrane recycling (Burden et al. 2004; Joubert et al. 2004; Braun et al. 2005; van Kerkhof et al. 2005). Endosome-to-TGN retrograde sorting is similarly complex, with contributions by clathrin in conjunction with AP1, PACS1, and epsinR (Meyer et al. 2000; Crump et al. 2001; Saint-Pol et al. 2004; Johannes and Popoff 2008; Shiba et al. 2010; Johannes and Wunder 2011). In addition, export of the mannose-6phosphate receptor from the late endosome appears to be regulated by the TIP47/Rab9 assembly (Lombardi et al. 1993; Díaz and Pfeffer 1998; Carroll et al. 2001; also see Bulankina et al. 2009).

\section{THE RETROMER COMPLEX}

Pioneering studies of protein sorting in the yeast endolysosomal system led to the identification of an endosomal coat protein complex named "retromer" that was found to be required for retrieval of a TGN sorting receptor (Vps10) from the endosome to the TGN (Seaman et al. 1998). The initial biochemical characterization of yeast retromer showed that it is composed of five proteins that can be dissociated into two subcomplexes (Horazdovsky et al. 1997; Seaman et al. 1997, 1998). One subcomplex contains a heterodimer of the Vps5 and Vps17 sorting nexins (SNX), which possess Bin/Amphiphysin/ Rvs (BAR) domains (SNX-BAR proteins) that can induce and/or sense the formation of membrane tubules (Carlton et al. 2004; van Weering et al. 2012a). The other retromer subunits constitute a trimeric complex of Vps26, Vps29, and Vps35 that does not have intrinsic membranebinding activity and relies on association with the Vps5-Vps17 for endosome recruitment (Seaman et al. 1998; Haft et al. 2000; Liu et al. 2012), or, independent of Vps5-Vps17, on association with the Rab7 ortholog, Ypt7, for recruitment to the vacuole membrane (Liu et al. 2012). The VPS26:VPS29:VPS35 heterotrimer has been shown to recognize cargo proteins and is therefore termed the cargo-selective complex (abbreviated “CSC”) (Seaman et al. 1998; Nothwehr et al. 2000; Norwood et al. 2011; Fjorback et al. 2012).

Whereas there is considerable divergence of sorting nexin proteins between species, CSC is an ancient protein assembly that emerged before the last common eukaryotic ancestor and has been strikingly conserved throughout eukaryotic evolution (Koumandou et al. 2011). Hence, the CSC trimer is considered to constitute the core functional component of retromer. Structural and sequence-based analysis predicts that human VPS35 is composed of 17 two-helix repeats that fold into an $\alpha$-solenoid that is typical of vesicle coat proteins (Hierro et al. 2007). Mammals express two Vps26 orthologs, VPS26A and VPS26B (Kerr et al. 2005), that possess an arrestin fold and bind to the highly conserved amino-terminal region of VPS35 (Shi et al. 2006; Collins et al. 2008). VPS29 possesses a metallophosphoesterase fold (Collins et al. 2005; Wang et al. 2005) and it binds to the carboxy-terminal portion of VPS35 (Collins et al. 2008; Norwood et al. 2011) where it is 
proposed to scaffold the helical solenoid of VPS35. Very little is known regarding the manner by which CSC recognizes cargo. Most retromer cargoes possess at least one simple hydrophobic motif, F/W-L-M/V, required for retromer-dependent sorting (Seaman 2007), and Vps35 has long been considered to provide the sole interface for cargo recognition. However, very recently, VPS26 was shown to bind a FANSHY sorting signal in the cytoplasmic domain of sorLA (Fjorback et al. 2012), and other proteins that associate with CSC, including sorting nexin-3 (SNX3), SNX27, and the retromer SNX-BARs, have been implicated in cargo recognition (Parks et al. 2001; Heydorn et al. 2004; Strochlic et al. 2007; Temkin et al. 2011; Steinberg et al. 2013). It is now appreciated that there exist multiple direct and indirect mechanisms by which CSC recognizes cargo.

\section{RETROMER AND THE ENDOSOME MATURATION PATHWAY}

By promoting the export of cargo from the endosome, retromer serves to "rescue" proteins from lysosome-mediated turnover and, hence, retromer function is intrinsically coupled to the endosome maturation pathway. Endosomal maturation itself is defined by an increasing number of intraluminal vesicles as the early endosome matures into the late endosome/multivesicular body, an increase in luminal acidification, endosome movement from the cell periphery toward a juxtanuclear localization, and the switching of two key endosome identity cues (Jean and Kiger 2012): the Rab5-positive, phosphatidylinositol-3-monophosphate (PtdIns(3)P)-enriched early endosome switches to become a Rab7-positive, phosphatidylinositol 3,5-bisphosphate $\left(\operatorname{PtdIns}(3,5) \mathrm{P}_{2}\right)$-enriched late endosome (Huotari and Helenius 2011).

The CSC does not itself bind to endosomes; instead, association to early and maturing late endosomes occurs through a variety of indirect mechanisms. The specific binding of SNX3 to PtdIns(3)P targets the CSC to early endosomes (Harterink et al. 2011; Vardarajan et al. 2012), whereas the ability of VPS35 to bind Rab7GTP associates the CSC with late endosomes
(Nakada-Tsukui et al. 2005; Rojas et al. 2008; Seaman et al. 2009; Balderhaar et al. 2010; Liu et al. 2012; Zelazny et al. 2013). Rab7 (Ypt7 in yeast) is a principal regulator of late endosome dynamics, and the interaction with VPS35 appears to serve a dual function in recruiting and/ or stabilizing CSC on the endosome membrane and in coordinating the timing of cargo export with endosome maturation. In yeast cells, depletion of Ypt7-GTP results in a deficiency in cargo export, even though CSC is assembled with SNX-BARs on the endosome membrane, suggesting that Ypt7 potentiates retromer-mediated cargo export (Liu et al. 2012). In further support for a role in $\mathrm{Rab} 7$ regulating retromer activity, in mammalian cells SNX-BAR-coated tubules bud predominantly from endosomes that have recently acquired Rab7 via Rab conversion (van Weering et al. 2012b). In yeast, CSC has been shown to inhibit Ypt7-regulated fusion of late endolysosomal organelles, suggesting that it can also influence endosome maturation indirectly by modulating the amount of Ypt7GTP (Liu et al. 2012). In mammalian cells, CSC limits Rab7 signaling through the recruitment of TBC1D5, a potential Rab7 GAP (Mukhopadhyay et al. 2007), to the endosome via direct binding to Vps29 (Seaman et al. 2009; Harbour et al. 2010). Interestingly, TBC1D5 also directly associates with the small ubiquitin-like protein LC3, a marker for autophagic membranes (Kabeya et al. 2000) and during starvation-induced autophagy TBC1D5 is relocalized from endosomes to LC3-positive autophagosomes (Popovic et al. 2012). As Rab7-GTP is required for autophagosome maturation, it is tempting to speculate that competitive binding of TBC1D5 to CSC or LC3 might serve to reprogram endosomal sorting to accommodate the ensuing autophagic flux to the lysosome.

\section{THE DIVERSITY OF RETROMER FUNCTION IN CELL FUNCTION AND ORGANISM PHYSIOLOGY}

Biochemical and genetic studies have identified a wide array of cargoes and cellular processes that require the CSC including the establishment of cell polarity through trafficking of 
Crumbs and Scribble (Pocha et al. 2011; Zhou et al. 2011; Lohia et al. 2012), regulation of the morphology and geometry of epithelial tubes during Drosophila development through transport of Serpentine (Dong et al. 2013), formation of Wnt morphogenic gradients through transport of the Wnt sorting receptor Wntless (Belenkaya et al. 2008; Franch-Marro et al. 2008; Pan et al. 2008; Port et al. 2008; Yang et al. 2008), transcytosis of the polymeric immunoglobulin receptor (Vergés et al. 2004), apoptotic cell clearance through sorting of the Caenorhabditis elegans phagocytic receptor CED-1 (Chen et al. 2010), cell polarity and organ initiation through trafficking of the Arabidopsis thaliana PIN auxin efflux carriers (Jaillais et al. 2007), and mitochondria to peroxisome transport through association with the mitochondrialanchored protein ligase MAPL (Braschi et al. 2010). Moreover, there is increasing realization that perturbed CSC function is linked to a number of human diseases. CSC deficiency plays a role in nonamyloidogenic versus amyloidogenic processing of amyloid precursor protein (APP) (He et al. 2005; Small et al. 2005; Muhammad et al. 2008; Wen et al. 2011; Choy et al. 2012) and the pathogenesis of Alzheimer's disease (Siegenthaler and Rajendran 2012). In addition, a specific VPS35 mutation, Asp620Asn, has been linked to late-onset autosomal-dominant familial Parkinson's disease (VilariñoGüell et al. 2011; Zimprich et al. 2011), the loci for human VPS26A has been genetically associated with type 2 diabetes in South Asians (Kooner et al. 2011), and the endosomal transport of various pathogens (Salmonella, Herpesvirus saimiri, Coxiella burnetii, human papillomavirus, Legionella pneumophila) and toxins (Shiga toxin) is also mediated in part by the CSC (Bujny et al. 2007, 2008; Popoff et al. 2007; Kingston et al. 2011; Finsel et al. 2013; Lipovsky et al. 2013; McDonough et al. 2013).

\section{FUNCTIONALLY DISTINCT RETROMER COMPLEXES}

It is now appreciated that retromer CSC functions as a component of multiple distinct sorting devices. The first indication of the diversity of retromer in multicellular organisms came from a biochemical and genetic study of the role of retromer in regulating the retrograde endosome-to-TGN transport of Wntless, and hence the formation of Wnt morphogenic gradients in C. elegans and Drosophila (Belenkaya et al. 2008; Franch-Marro et al. 2008; Pan et al. 2008; Port et al. 2008; Yang et al. 2008). Here the functional retromer is composed of the direct binding of the CSC to the early endosome associated non-BAR domain-containing SNX3, an association that is independent of the SNXBAR retromer subunits (Harterink et al. 2011; Zhang et al. 2011). Genetic loss of SNX3 or CSC in C. elegans and Drosophila, leads to the missorting of internalized Wntless into the lysosomal degradative pathway (this is also observed in mammalian cell culture upon RNAi-mediated suppression), a reduction in the steady-state level of Wntless, and a defect in Wnt secretion and hence Wnt gradient formation (Harterink et al. 2011). Thus, although the SNX3 retromer and SNX-BAR retromer both mediate endosome-to-TGN transport, they constitute distinct, cargo-specific pathways. Indeed, in C. elegans, the retromer-mediated sorting of CED-1 is SNX-BAR-retromer dependent but is independent of the SNX3 retromer (Chen et al. 2010; Harterink et al. 2011; Lu et al. 2011). Furthermore, the morphological profile of each transport carrier is distinct: SNX-BAR retromer residing on nonbranched tubules $170-230 \mathrm{~nm}$ in length and $20-50 \mathrm{~nm}$ in diameter (Mari et al. 2008), whereas SNX3 retromer is associated with small clathrin-coated vesicular profiles (Harterink et al. 2011). These results indicate that there are distinct forms of retromer that are defined via CSC associations with different sorting nexins and that these retromers act on distinct sets of cargo.

Besides its well-established roles in endosome-to-TGN trafficking, it has recently emerged that retromer also plays a central role in endosome-to-plasma membrane recycling (Feinstein et al. 2011; Temkin et al. 2011). In mammalian cells, the endosomal recycling of the $\beta 2$-adrenergic receptor $(\beta 2-\mathrm{AR})$ is dependent on the presence of a carboxy-terminal PDZ ligand that acts as a sorting signal for direct 
recycling to the plasma membrane (Cao et al. 1999). The PDZ domain of SNX27 binds directly to this signal, and by engaging the CSC mediates $\beta 2$-AR recycling through SNX-BARretromer decorated tubules (Lauffer et al. 2010; Temkin et al. 2011). Indeed, the CSC constitutes a major endosome recycling hub. In HeLa cells, the endosome-to-plasma membrane recycling of $>150$ transmembrane spanning proteins would appear to be dependent on the CSC (Steinberg et al. 2013). Of these, $>70$ cargos require the presence of SNX27 for their recycling, many of which contain PDZ ligands, whereas others contain $\mathrm{NPxY} / \mathrm{NxxY}$ sorting motifs (Steinberg et al. 2013). Because SNX27 harbors a functional FERM-like domain that can engage NPxY/NxxY-based sorting signals (Ghai et al. 2013), the cargo adaptor function of SNX27 in retromer-mediated recycling appears to embrace both PDZ ligand and NPxY/ NxxY sorting motif recognition. Like the situation with the SNX3 retromer, loss of SNX27 or CSC leads to cargo missorting into lysosomalmediated degradation (Temkin et al. 2011; Steinberg et al. 2013). This reinforces that a primary role of the CSC, and its associated cargo adaptors, is to prevent missorting of selected cargoes into the lysosomal degradative pathway.

Interestingly, retromer-mediated recycling of the $\beta 2$-AR occurs through a specialized actin-stabilized tubular subdomain (Puthenveedu et al. 2010). Consistent with this, SNX27 lies at the core of a multiprotein complex defined by the binding to retromer, and the independent association with the retromer SNX-BARs and the Wiskott-Aldrich syndrome protein and SCAR homolog (WASH) (Temkin et al. 2011; Steinberg et al. 2013), which by regulating the activity of the Arp2/3 complex mediates the formation of branched actin filaments on the endosomal network (Derivery et al. 2009; Gomez and Billadeau 2009). Given the specific function of each individual component of this multiprotein SNX27-containing complex, one intriguing question is: How does retromer coordinate cargo capture and enrichment with the extensive membrane remodeling that is required to generate a cargo-enriched transport carrier?

\section{COUPLING RETROMER SORTING TO CARGO EXPORT}

Export of cargo from the endosome by SNXBAR retromer is initiated by the capture of cargo by CSC and other associated adaptors on the vacuolar portion of the endosome thereby preventing their entry into the lysosomal degradative pathway. A key consideration for understanding CSC function is that the functional units of membranes of the endocytic system are specialized microdomains, defined as assemblies of cargo proteins, lipids, and peripherally associated proteins, that partition into discrete networks within the plane of the membrane (Huotari and Helenius 2011). We speculate that CSC defines a subdomain(s) within the endosome membrane that promotes the efficient capture and enrichment of cargo, preventing their entry into the lysosomal degradative pathway and preparing them for subsequent inclusion into the TEN, or for the case of SNX3 retromer, vesicular transport carriers (Fig. 2). Cargo capture takes place on the vacuolar portion of the endosome, which is a region that is essentially flat (at the molecular scale), and subsequent events direct captured cargo into tubules of high relative membrane curvature that are coated with SNX-BAR retromer. Central to the formation of the TEN is the intrinsic ability of a subset of SNX-BAR proteins to selfassemble via interactions involving the BAR domain that can drive and/or stabilize the formation of membrane tubules (Carlton et al. 2004; Wassmer et al. 2007, 2009; van Weering et al. 2012a). In this respect, SNX-BAR proteins constitute an endosomal coat complex (Attar and Cullen 2010; Cullen and Korswagen 2012; Seaman 2012) and a major challenge for the field is to elucidate the mechanism(s) by which CSC orchestrates cargo capture and enrichment with packaging into the formation of these tubular transport carriers.

Although retromer function opposes sorting into the degradative lysosomal pathway, the emerging principles of degradative sorting may be instructive for understanding CSC-dependent packaging of cargo into the TEN. In the degradative pathway, cargo is sorted into vesi- 


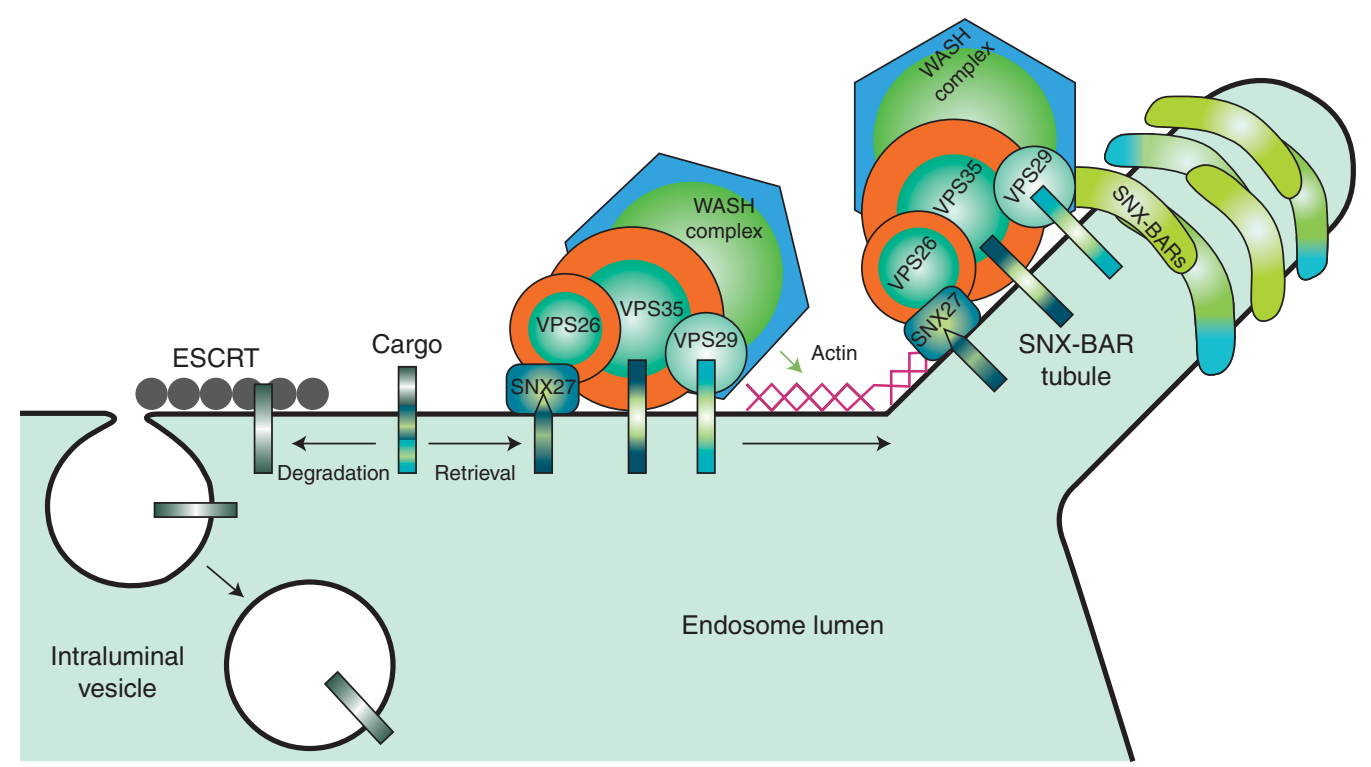

Figure 2. SNX-BAR-retromer-mediated cargo exit from lysosomal-mediated degradation. The VPS26:VPS29: VPS35 CSC engage cargo in a signal-dependent manner. Through WASH-mediated actin polymerization a cargo-enriched endosome subdomain is assembled thereby avoiding ESCRT-mediated sorting into forming intraluminal vesicles. Subsequent transport into recycling pathways back to the plasma membrane or retrograde transport to the TGN is mediated through retromer SNX-BAR-mediated tubule formation. Actin polymerization may aid further membrane remodeling and the efficiency of tubule scission to form a cargo-enriched tubular transport carrier.

cles that bud into the lumen of the endosome. Central to our understanding of sorting into intraluminal vesicles is the notion that cargo is first captured in a signal-dependent manner and enriched within a subdomain of the endosomal limiting membrane from where the generation of negative membrane curvature (i.e., bending the endosomal membrane away from the cytosol) occurs concomitantly with the cargo entering intraluminal vesicles (ILVs) (Hurley and Hanson 2010; Henne et al. 2011). Degradative cargo is captured by a cargo-sorting receptor termed "endosomal sorting complex required for transport-0 (ESCRT-0)" and their lateral mobility restricted within an endosomal subdomain defined by ESCRT-0 (Wollert and Hurley 2010) and the formation of a clathrin bilayer coat (Sachse et al. 2002). Subsequently, ESCRT-III promotes the budding of the ILV (Teis et al. 2010; Wollert and Hurley 2010; Henne et al. 2012). Unlike cytoplasmic transport vesicles, ILVs are not surrounded by a pro- teinaceous coat, implying that once cargo is captured, it enters the forming ILV by default. The insights from endosomal sorting complex required for transport (ESCRT)-dependent sorting point to the key function of establishing a domain of entrapped cargo that serves to direct it into the budding transport carrier. CSC serves a similar function to ESCRT-0 in the signal-dependent capture of cargo that is subsequently transferred into a tubule/vesicle that buds from the endosome into the cytoplasm. In this view, the cargo burden of the transport carrier is defined chiefly by CSC and its associated adaptors (Fig. 3), rather than the specific sorting nexin that functions in sculpting the transport carrier.

How does CSC mediate cargo sorting? One possibility is that it captures and concentrates cargo via a multivalent binding site to CSC proteins. Clear evidence for this is presently lacking, but it is in line with the lack of robust oligomerization of CSC in solution (Norwood 
C. Burd and P.J. Cullen
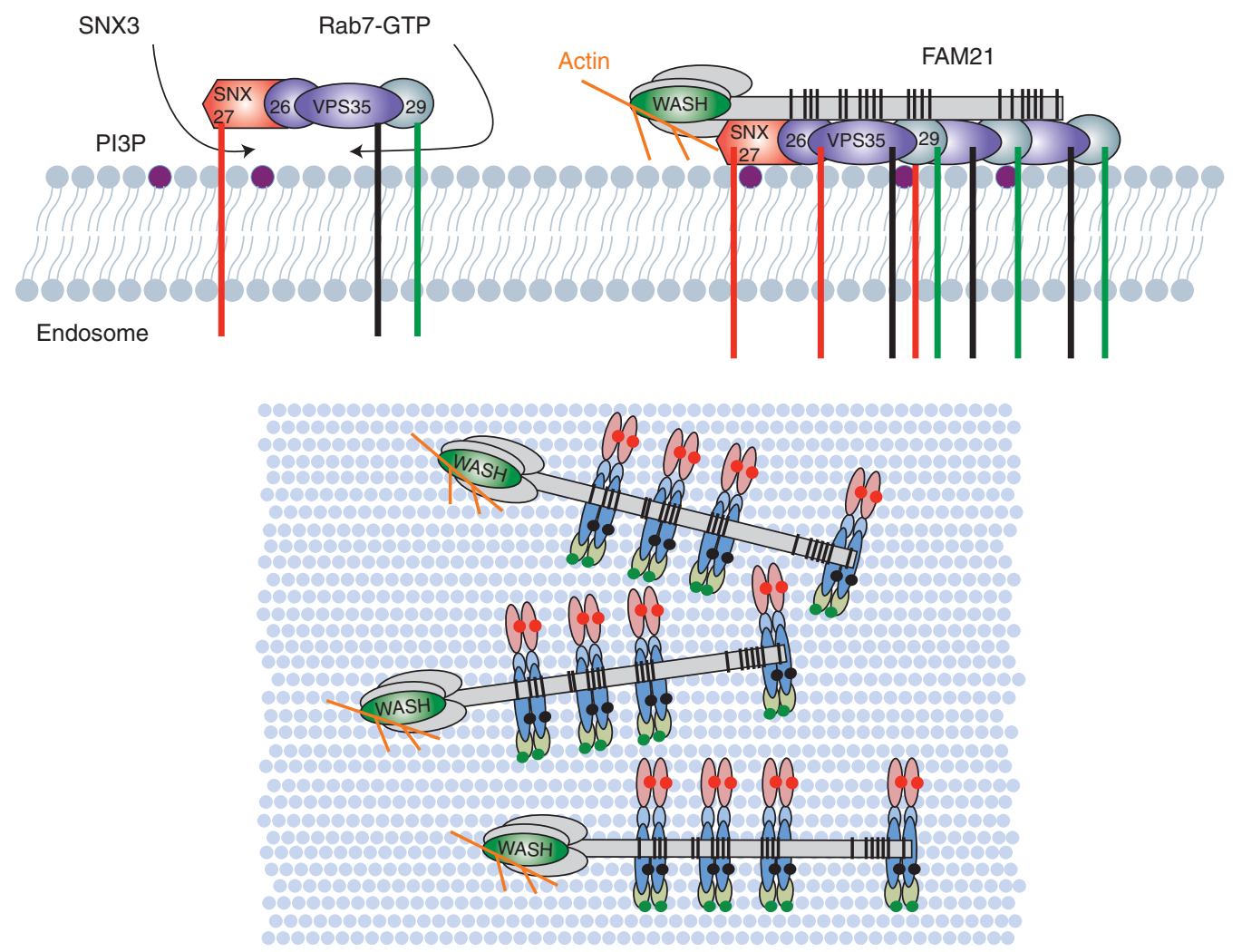

Figure 3. A pictorial representation of the proposed CSC retrieval subdomain on the endosomal surface (based on data from Jia et al. 2012). The CSC is associated with the cytosolic face of the early endosome and the maturing late endosome through association with the phosphatidylinositol 3-monophosphate (PI3P)-binding SNX3 and Rab7-GTP, respectively. In addition to cargo selection mediated by the CSC, associated adaptors also engage cargo (the PI3P-binding SNX27 is depicted). Through association of the unstructured tail of FAM21, multiple CSCs, along with their associated cargoes, become enriched into a retrieval subdomain (retrieval zone) in which lateral mobility is restricted as a result of WASH-mediated actin polymerization. In the lower bird's-eye view, two associated CSCs are shown to reflect evidence for dimeric assemblies (Norwood et al. 2011).

et al. 2011). Emerging evidence suggests that actin dynamics on the endosome membrane, regulated by CSC, is a key factor that influences retromer-dependent sorting (Gomez and Billadeau 2009). The WASH complex is formed from the assembly of five proteins: strumpellin, FAM21, SWIP, ccdc53, and WASH (Derivery and Gautreau 2010). It is recruited to the endosome membrane through a complex mechanism that in part relies on the binding to the VPS35 CSC subunit (Gomez and Billadeau 2009; Harbour et al. 2010, 2012; Derivery et al. 2012; Jia et al. 2012; Helfer et al. 2013; Park et al. 2013). On the endosome membrane, the WASH complex activates the Arp2/3 complex, which mediates the nucleation of actin branching to a preexisting actin filament (Rotty et al. 2013). In cultured cells, loss of WASH results in collapse of the endolysosomal system into enlarged endosome-like compartments in which degradative cargo, recycling cargo, retrograde cargo, and lysosomal proteins accumulate (i.e., a missorting phenotype) (Duleh and Welch 2010; Derivery et al. 2012; Gomez et al. 2012; Piotrowski et al. 2013). Interestingly, the carboxy-terminal region of FAM21 possesses 21 copies of a motif distributed over nearly 1000 unstructured amino acids that is recognized by VPS35 (Jia 
et al. 2012). The multivalent nature of this interaction (i.e., one FAM21 can associate with multiple copies of CSC) has been suggested to effectively sense the density of CSC and associated cargo adaptors (and hence the density of captured cargo) thereby coordinating cargo capture and enrichment with the formation of a branched actin network that restricts lateral diffusion of the enriched cargo into other sorting pathways (Fig. 3) (Jia et al. 2012). The presence of actin subdomains on the endosome membrane is consistent with such a cargo "retrieval zone" (Sachse et al. 2002; Derivery et al. 2012), akin to the degradative sorting zone formed by ESCRT proteins. Whether these retrieval zones also act to modify the posttranslational status of captured cargo (e.g., ubiquitination and/or phosphorylation), is an interesting open question. Indeed, in higher metazoans VPS35 binds the E3 RING ubiquitin ligase, MAGE-L2-TRIM27, an interaction that localizes this enzyme to endosomes, and through K63linked ubiquitination of WASH at lysine 220 relieves an autoinhibited WASH conformation leading to activation of endosomal actin polymerization (Hao et al. 2013). Loss of WASH also results in elongated SNX-BAR tubules, raising the possibility that a localized activation of WASH results in a burst of actin polymerization, spatially localized with the retrieval zone, that contributes to the efficiency of fission of sorting tubules coated with filamentous actin (Derivery et al. 2009; Gomez and Billadeau 2009; Puthenveedu et al. 2010). Clearly, understanding the interrelationship between retromer, cargo, and the activity of the WASH complex in regulating the dynamics of actin turnover is sure to generate exciting insight into the formation of sorting subdomains on the endosome membrane.

\section{CONCLUDING REMARKS AND FUTURE PERSPECTIVES}

Although significant research will be required to further define the specific endosomal recycling and retrograde transport pathways, an increasingly important question becomes one of how degradative sorting versus recycling versus retrograde transport are coordinated to achieve a system capable of actively remodeling sorting itineraries in response to changing metabolic and environmental cues. By addressing this complex question much needed insight will be gained into the wiring between endosomal sorting and the varying physiological needs of cells in tissues and organs, and also a greater understanding of how deficiencies in endosomal sorting, either at the level of individual cargo or in the context of specific coat complexes and their associated protein assemblies, underlie a variety of human diseases. The problem is to identify those elements within the system that constitute the key "conductors" that broadly control endosome sorting. We consider that a growing body of evidence strongly points toward retromer, and in particular the CSC, as a vital evolutionary conserved conductor of sorting within the endosomal network. Exploring the transcriptional and translational control of this heterotrimer and the effects of posttranslation modification on its assembly, endosome association and wider protein:protein interactome are likely to generate significant new insight into the remodeling of endosomal sorting during cell function, organism development, and physiology, and perhaps most importantly, human health and disease.

\section{ACKNOWLEDGMENTS}

We thank members of our laboratories for helpful discussions and critical review of the manuscript, and Matthew Gallon for Figure 2. Work in the authors' laboratories is supported by grants from the U.S. National Institutes of Health (GM061221 to C.B.), The Wellcome Trust (089928, 083474, and 083474 to P.J.C.), Biotechnology and Biological Sciences Research Council (BB/I011412/1 to P.J.C.), and Medical Research Council (MK/K018299/1 to P.J.C.).

\section{REFERENCES}

Attar N, Cullen PJ. 2010. The retromer complex. Adv Enzyme Regul 50: 216-236.

Balderhaar HJ, Arlt H, Ostrowicz C, Bröcker C, Sündermann F, Brandt R, Babst M, Ungermann C. 2010. The Rab GTPase Ypt7 is linked to retromer-mediated recep- 


\section{Burd and P.J. Cullen}

tor recycling and fusion at the yeast late endosome. J Cell Sci 123: 4085-4094.

Belenkaya TY, Wu Y, Tang X, Zhou B, Cheng L, Sharma YV, Yan D, Selva EM, Lin X. 2008. The retromer complex influences Wnt secretion by recycling wntless from endosomes to the trans-Golgi network. Dev Cell 14: 120-131.

Bonifacino JS, Rojas R. 2006. Retrograde transport from endosomes to the trans-Golgi network. Nat Rev Mol Cell Biol 7: 568-579.

Braschi E, Goyon V, Zunino R, Mohanty A, Xu L, McBride HM. 2010. Vps35 mediates vesicle transport between the mitochondria and peroxisomes. Curr Biol 20: 13101315.

Braun A, Pinyol R, Dahlhaus R, Koch D, Fonarev P, Grant BD, Kessels MM, Qualmann B. 2005. EHD proteins associate with syndapin I and II and such interactions play a crucial role in endosomal recycling. Mol Biol Cell 16: 3642-3658.

Bujny MV, Popoff V, Johannes L, Cullen PJ. 2007. The retromer component sorting nexin-1 is required for efficient retrograde transport of Shiga toxin from early endosome to the trans-Golgi network. J Cell Sci 120: 2010-2021.

Bujny MV, Ewels PA, Humphrey S, Attar N, Jepson MA, Cullen PJ. 2008. Sorting nexin-1 defines an early phase of Salmonella-containing vacuole remodeling during Salmonella infection. J Cell Sci 121: 2027-2036.

Bulankina AV, Deggerich A, Wenzel D, Mutenda K, Wittmann JG, Rudolph MG, Burger KN, Höning S. 2009. TIP47 functions in the biogenesis of lipid droplets. J Cell Biol 185: 641-655.

Burd CG. 2011. Physiology and pathology of endosome-toGolgi retrograde sorting. Traffic 12: 948-955.

Burden JJ, Sun XM, García AB, Soutar AK. 2004. Sorting motifs in the intracellular domain of the low density lipoprotein receptor interact with a novel domain of sorting nexin-17. J Biol Chem 279: 16237-16245.

Cao TT, Deacon HW, Reczek D, Bretscher A, von Zastrow M. 1999. A kinase-regulated PDZ-domain interaction controls endocytic sorting of the $\beta 2$-adrenergic receptor. Nature 401: 286-290.

Carlton J, Bujny M, Peter BJ, Oorschot VM, Rutherford A, Mellor H, Klumperman J, McMahon HT, Cullen PJ. 2004. Sorting nexin-1 mediates tubular endosome-toTGN transport through coincidence sensing of high-curvature membranes and 3-phosphoinositides. Curr Biol 14: $1791-800$.

Carroll KS, Hanna J, Simon I, Krise J, Barbero P, Pfeffer SR. 2001. Role of Rab9 GTPase in facilitating receptor recruitment by TIP47. Science 292: 1373-1376.

Chen D, Xiao H, Zhang K, Wang B, Gao Z, Jian Y, Qi X, Sun J, Miao L, Yang C. 2010. Retromer is required for apoptotic cell clearance by phagocytic receptor recycling. Science 327: 1261-1264.

Choy RW, Cheng Z, Schekman R. 2012. Amyloid precursor protein (APP) traffics from the cell surface via endosomes for amyloid $\beta$ (A $\beta)$ production in the trans-Golgi network. Proc Natl Acad Sci 109: E2077-E2082.

Collins BM, Skinner CF, Watson PJ, Seaman MN, Owen DJ. 2005. Vps29 has a phosphoesterase fold that acts as a protein interaction scaffold for retromer assembly. Nat Struct Mol Biol 12: 594-602.

Collins BM, Norwood SJ, Kerr MC, Mahony D, Seaman MN, Teasdale RD, Owen DJ. 2008. Structure of Vps26B and mapping of its interaction with the retromer protein complex. Traffic 9: 366-379.

Crump CM, Xiang Y, Thomas L, Gu F, Austin C, Tooze SA, Thomas G. 2001. PACS-1 binding to adaptors is required for acidic cluster motif-mediated protein traffic. EMBO J 20: 2191-2201.

Cullen PJ, Korswagen HC. 2012. Sorting nexins provide diversity for retromer-dependent trafficking events. Nat Cell Biol 14: 29-37.

Dai J, Li J, Bos E, Porcionatto M, Premont RT, Bourgoin S, Peters PJ, Hsu VW. 2004. ACAP1 promotes endocytic recycling by recognizing recycling sorting signals. Dev Cell 7: 771-776.

Derivery E, Gautreau A. 2010. Evolutionary conservation of the WASH complex, an actin polymerization machine involved in endosomal fission. Commun Integr Biol 3: 227-230.

Derivery E, Sousa C, Gautier JJ, Lombard B, Loew D, Gautreau A. 2009. The Arp2/3 activator WASH controls the fission of endosomes through a large multiprotein complex. Dev Cell 17: 712-723.

Derivery E, Helfer E, Henriot V, Gautreau A. 2012. Actin polymerization controls the organization of WASH domains at the surface of endosomes. PLoS ONE 7: e39774.

Díaz E, Pfeffer SR. 1998. TIP47: A cargo selection device for mannose 6-phosphate receptor trafficking. Cell 93: 433-443.

Dong B, Kakihara K, Otani T, Wada H, Hayashi S. 2013. Rab9 and retromer regulate retrograde trafficking of luminal protein required for epithelial tube length control. Nat Commun 4: 1358.

Duleh SN, Welch MD. 2010. WASH and the Arp2/3 complex regulate endosome shape and trafficking. Cytoskeleton (Hoboken) 67: 193-206.

Feinstein TN, Wehbi VL, Ardura JA, Wheeler DS, Ferrandon S, Gardella TJ, Vilardaga JP. 2011. Retromer terminates the generation of cAMP by internalized PTH receptors. Nat Chem Biol 7: 278-284.

Finsel I, Ragaz C, Hoffmann C, Harrison CF, Weber S, van Rahden VA, Johannes L, Hilbi H. 2013. The Legionella effector RidL inhibits retrograde trafficking to promote intracellular replication. Cell Host Microbe 14: 38-50.

Fjorback AW, Seaman M, Gustafsen C, Mehmedbasic A, Gokool S, Wu C, Militz D, Schmidt V, Madsen P, Nyengaard JR, et al. 2012. Retromer binds the FANSHY sorting motif in SorLA to regulate amyloid precursor protein sorting and processing. J Neurosci 32: 1467-1480.

Franch-Marro X, Wendler F, Guidato S, Griffith J, BaenaLopez A, Itasaki N, Maurice MM, Vincent JP. 2008. Wingless secretion requires endosome-to-Golgi retrieval of Wntless/Evi/Sprinter by the retromer complex. Nat Cell Biol 10: 170-177.

Ghai R, Bugarcic A, Liu H, Norwood SJ, Skeldal S, Coulson EJ, Li SS, Teasdale RD, Collins BM. 2013. Structural basis for endosomal trafficking of diverse transmembrane cargos by PX-FERM proteins. Proc Natl Acad Sci 110: E643E652. 
Gomez TS, Billadeau DD. 2009. A FAM21-containing WASH complex regulates retromer-dependent sorting. Dev Cell 17: 699-711.

Gomez TS, Gorman JA, de Narvajas AA, Koenig AO, Billadeau DD. 2012. Trafficking defects in WASH-knockout fibroblasts originate from collapsed endosomal and lysosomal networks. Mol Biol Cell 23: 3215-3228.

Grant BD, Donaldson JG. 2009. Pathways and mechanisms of endocytic recycling. Nat Rev Mol Cell Biol 10: 597608.

Haft CR, de la Luz Sierra M, Bafford R, Lesniak MA, Barr VA, Taylor SI. 2000. Human orthologs of yeast vacuolar protein sorting proteins Vps26, 29, and 35: Assembly into multimeric complexes. Mol Biol Cell 11: 4105-4116.

Hao YH, Doyle JM, Ramanathan S, Gomez TS, Jia D, Xu M, Chen ZJ, Billadeau DD, Rosen MK, Potts PR. 2013. Regulation of WASH-dependent actin polymerization and protein trafficking by ubiquitination. Cell 152: $1051-$ 1064.

Harbour ME, Breusegem SY, Antrobus R, Freeman C, Reid E, Seaman MN. 2010. The cargo-selective retromer complex is a recruiting hub for protein complexes that regulate endosomal tubule dynamics. J Cell Sci 123: $3703-$ 3717.

Harbour ME, Breusegem SY, Seaman MN. 2012. Recruitment of the endosomal WASH complex is mediated by the extended "tail" of Fam21 binding to the retromer protein Vps35. Biochem J 442: 209-220.

Harterink M, Port F, Lorenowicz MJ, McGough IJ, Silhankova M, Betist MC, van Weering JR, van Heesbeen RG, Middelkoop TC, Basler K, et al. 2011. A SNX3-dependent retromer pathway mediates retrograde transport of the Wnt sorting receptor Wntless and is required for Wnt secretion. Nat Cell Biol 13: 914-923.

He X, Li F, Chang WP, Tang J. 2005. GGA proteins mediate the recycling pathway of memapsin 2 (BACE). J Biol Chem 280: 11696-11703.

Helfer E, Harbour ME, Henriot V, Lakisic G, Sousa-Blin C Volceanov L, Seaman MN, Gautreau A. 2013. Endosomal recruitment of the WASH complex: Active sequences and mutations impairing interaction with the retromer. Biol Cell 105: 191-207.

Henne WM, Buchkovich NJ, Emr SD. 2011. The ESCRT pathway. Dev Cell 21: 77-91.

Henne WM, Buchkovich NJ, Zhao Y, Emr SD. 2012. The endosomal sorting complex ESCRT-II mediates the assembly and architecture of ESCRT-III helices. Cell 151: 356-371.

Heydorn A, Søndergaard BP, Ersbøll B, Holst B, Nielsen FC, Haft CR, Whistler J, Schwartz TW. 2004. A library of 7TM receptor C-terminal tails. Interactions with the proposed post-endocytic sorting proteins ERM-binding phosphoprotein 50 (EBP50), $\mathrm{N}$-ethylmaleimide-sensitive factor (NSF), sorting nexin 1 (SNX1), and G protein-coupled receptor-associated sorting protein (GASP). J Biol Chem 279: 54291-54303.

Hierro A, Rojas AL, Rojas R, Murthy N, Effantin G, Kajava AV, Steven AC, Bonifacino JS, Hurley JH. 2007. Functional architecture of the retromer cargo-recognition complex. Nature 449: 1063-1067.

Horazdovsky BF, Davies BA, Seaman MN, McLaughlin SA, Yoon S, Emr SD. 1997. A sorting nexin-1 homologue,
Vps5p, forms a complex with Vps17p and is required for recycling the vacuolar protein-sorting receptor. $\mathrm{Mol}$ Biol Cell 8: 1529-1541.

Hsu VW, Bai M, Li J. 2012. Getting active: Protein sorting in endocytic recycling. Nat Rev Mol Cell Biol 13: 323-328.

Huotari J, Helenius A. 2011. Endosome maturation. EMBO J 30: 3481-3500.

Hurley JH, Hanson PI. 2010. Membrane budding and scission by the ESCRT machinery: It's all in the neck. Nat Rev Mol Cell Biol 11: 556-566.

Jaillais Y, Santambrogio M, Rozier F, Fobis-Loisy I, Miège C, Gaude T. 2007. The retromer protein VPS29 links cell polarity and organ initiation in plants. Cell 130: 10571070.

Jean S, Kiger AA. 2012. Coordination between Rab GTPase and phosphoinositide regulation and functions. Nat Rey Mol Cell Biol 13: 463-470.

Jia D, Gomez TS, Billadeau DD, Rosen MK. 2012. Multiple repeat elements within the FAM21 tail link the WASH actin regulatory complex to the retromer. Mol Biol Cell 23: 2352-2361.

Johannes L, Popoff V. 2008. Tracing the retrograde route in protein trafficking. Cell 135: 1175-1187.

Johannes L, Wunder C. 2011. Retrograde transport: Two (or more) roads diverged in an endosomal tree? Traffic 12: 956-962.

Joubert L, Hanson B, Barthet G, Sebben M, Claeysen S, Hong W, Marin P, Dumuis A, Bockaert J. 2004. New sorting nexin (SNX27) and NHERF specifically interact with the $5-\mathrm{HT}_{4(\mathrm{a})}$ receptor splice variant: Roles in receptor targeting. J Cell Sci 117: 5367-5379.

Kabeya Y, Mizushima N, Ueno T, Yamamoto A, Kirisako T, Noda T, Kominami E, Ohsumi Y, Yoshimori T. 2000. LC3, a mammalian homologue of yeast Apg8p, is localized in autophagosome membranes after processing. $E M B O J$ 19: $5720-5728$.

Kerr MC, Bennetts JS, Simpson F, Thomas EC, Flegg C, Gleeson PA, Wicking C, Teasdale RD. 2005. A novel mammalian retromer component, Vps26B. Traffic 6: 991-1001.

Kingston D, Chang H, Ensser A, Lee HR, Lee J, Lee SH, Jung JU, Cho NH. 2011. Inhibition of retromer activity by herpesvirus saimiri tip leads to CD4 downregulation and efficient T cell transformation. J Virol 85: 1062710638.

Kooner JS, Saleheen D, Sim X, Sehmi J, Zhang W, Frossard P, Been LF, Chia KS, Dimas AS, Hassanali N, et al. 2011 Genome-wide association study in individuals of South Asian ancestry identifies six new type 2 diabetes susceptibility loci. Nat Genet 43: 984-989.

Koumandou VL, Klute MJ, Herman EK, Nunez-Miguel R, Dacks JB, Field MC. 2011. Evolutionary reconstruction of the retromer complex and its function in Trypanosoma brucei. J Cell Sci 124: 1496-1509.

Lauffer BE, Melero C, Temkin P, Lei C, Hong W, Kortemme T, von Zastrow M. 2010. SNX27 mediates PDZ-directed sorting from endosomes to the plasma membrane. J Cell Biol 190: 565-574.

Li J, Peters PJ, Bai M, Dai J, Bos E, Kirchhausen T, Kandror KV, Hsu VW. 2007. An ACAP1-containing clathrin coat complex for endocytic recycling. J Cell Biol 178: 453-464. 


\section{Burd and P.J. Cullen}

Lipovsky A, Popa A, Pimienta G, Wyler M, Bhan A, Kuruvilla L, Guie MA, Poffenberger AC, Nelson CD, Atwood WJ, et al. 2013. Genome-wide siRNA screen identified the retromer as a cellular entry factor for human papillomavirus. Proc Natl Acad Sci 110: 7452-7457.

Liu TT, Gomez TS, Sackey BK, Billadeau DD, Burd CG. 2012. Rab GTPase regulation of retromer-mediated cargo export during endosome maturation. $\mathrm{Mol}$ Biol Cell 23 2505-2515.

Lohia M, Qin Y, Macara IG. 2012. The Scribble polarity protein stabilizes E-cadherin/p120-catenin binding and blocks retrieval of E-cadherin to the Golgi. PLoS ONE 7: e51130.

Lombardi D, Soldati T, Riederer MA, Goda Y, Zerial M, Pfeffer SR. 1993. Rab9 functions in transport between late endosomes and the trans-Golgi network. EMBO J 12: $677-682$.

Lu N, Shen Q, Mahoney TR, Liu X, Zhou Z. 2011. Three sorting nexins drive the degradation of apoptotic cells in response to PtdIns(3)P signaling. Mol Biol Cell 22: 354374 .

Mari M, Bujny MV, Zeuschner D, Geerts WJ, Griffith J, Petersen CM, Cullen PJ, Klumperman J, Geuze HJ. 2008. SNX1 defines an early endosomal recycling exit for sortilin and mannose 6-phosphate receptors. Traffic 9: 380-393.

Maxfield FR, McGraw TE. 2004. Endocytic recycling. Nat Rev Mol Cell Biol 5: 121-132.

Mayor S, Presley JF, Maxfield FR. 1993. Sorting of membrane components from endosomes and subsequent recycling to the cell surface occurs by a bulk flow process. J Cell Biol 121: 1257-1269.

McDonough JA, Newton HJ, Klum S, Swiss R, Agaisse H, Roy CR. 2013. Host pathways important for Coxiella burnetii infection revealed by genome-wide RNA interference screening. MBio 4: e00606-12.

Meyer C, Zizioli D, Lausmann S, Eskelinen EL, Hamann J, Saftig P, von Figura K, Schu P. 2000. $\mu 1$ A-adaptin-deficient mice: Lethality, loss of AP1 binding and rerouting of mannose 6-phosphate receptors. EMBO J 19: 2193 2203.

Muhammad A, Flores I, Zhang H, Yu R, Staniszewski A Planel E, Herman M, Ho L, Kreber R, Honig LS, et al. 2008. Retromer deficiency observed in Alzheimer's disease causes hippocampal dysfunction, neurodegeneration, and $\mathrm{A} \beta$ accumulation. Proc Natl Acad Sci 105: 7327-7332.

Mukhopadhyay A, Pan X, Lambright DG, Tissenbaum HA 2007. An endocytic pathway as a target of tubby for regulation of fat storage. EMBO Rep 8: 931-938.

Nakada-Tsukui K, Saito-Nakano Y, Ali V, Nozaki T. 2005. A retromer-like complex is a novel Rab7 effector that is involved in the transport of the virulence factor cysteine protease in the enteric protozoan parasite Entamoeba histolytica. Mol Biol Cell 16: 5294-5303.

Norwood SJ, Shaw DJ, Cowieson NP, Owen DJ, Teasdale RD, Collins BM. 2011. Assembly and solution structure of the core retromer protein complex. Traffic 12: 56-71.

Nothwehr SF, Ha SA, Bruinsma P. 2000. Sorting of yeast membrane proteins into an endosome-to-Golgi pathway involves direct interaction of their cytosolic domains with Vps35p. J Cell Biol 151: 297-310.
Pan CL, Baum PD, Gu M, Jorgensen EM, Clark SG, Garriga G. 2008. C. elegans AP2 and retromer control Wnt signaling by regulating mig-14/Wntless. Dev Cell 14: 132139.

Parachoniak CA, Luo Y, Abella JV, Keen JH, Park M. 2011. GGA3 functions as a switch to promote Met receptor recycling, essential for sustained ERK and cell migration. Dev Cell 20: 751-763.

Park L, Thomason PA, Zech T, King JS, Veltman DM, Carnell M, Ura S, Machesky LM, Insall RH. 2013. Cyclical action of the WASH Complex: FAM21 and capping protein drive WASH recycling, not initial recruitment. Dev Cell 24: 169-181.

Parks WT, Frank DB, Huff C, Renfrew Haft C, Martin J, Meng X, de Caestecker MP, McNally JG, Reddi A, Taylor SI, et al. 2001. Sorting nexin 6, a novel SNX, interacts with the transforming growth factor- $\beta$ family of receptor serine-threonine kinases. J Biol Chem 276: 19332-19339.

Piotrowski JT, Gomez TS, Schoon RA, Mangalam AK, Billadeau DD. 2013. WASH knockout T cells demonstrate defective receptor trafficking, proliferation, and effector function. Mol Cell Biol 33: 958-973.

Pocha SM, Wassmer T, Niehage C, Hoflack B, Knust E. 2011. Retromer controls epithelial cell polarity by trafficking the apical determinant Crumbs. Curr Biol 21: 11111117.

Popoff V, Mardones GA, Tenza D, Rojas R, Lamaze C, Bonifacino JS, Raposo G, Johannes L. 2007. The retromer complex and clathrin define an early endosomal retrograde exit site. J Cell Sci 120: 2022-2031.

Popovic D, Akutsu M, Novak I, Harper W, Behrends C, Dikic I. 2012. Rab GAPs in autophagy: Regulation of endocytic and autophagy pathways by direct binding to human ATG8 modifiers. Mol Cell Biol 32: 1733-1744.

Port F, Kuster M, Herr P, Furger E, Bänziger C, Hausmann G, Basler K. 2008. Wingless secretion promotes and requires retromer-dependent cycling of Wntless. Nat Cell Biol 10: $178-185$.

Puthenveedu MA, Lauffer B, Temkin P, Vistein R, Carlton P, Thorn K, Taunton J, Weiner OD, Parton RG, von Zastrow M. 2010. Sequence-dependent sorting of recycling proteins by actin-stabilized endosomal microdomains. Cell 143: $761-773$.

Rojas R, van Vlijmen T, Mardones GA, Prabhu Y, Rojas AL, Mohammed S, Heck AJ, Raposo G, van der Sluijs P, Bonifacino JS. 2008. Regulation of retromer recruitment to endosomes by sequential action of Rab5 and Rab7. J Cell Biol 183: 513-526.

Rotty JD, Wu C, Bear JE. 2013. New insights into the regulation and cellular functions of the ARP2/3 complex. Nat Rev Mol Cell Biol 14: 7-12.

Sachse M, Urbé S, Oorschot V, Strous GJ, Klumperman J. 2002. Bilayered clathrin coats on endosomal vacuoles are involved in protein sorting toward lysosomes. Mol Biol Cell 13: 1313-1328.

Saint-Pol A, Yélamos B, Amessou M, Mills IG, Dugast M, Tenza D, Schu P, Antony C, McMahon HT, Lamaze C, et al. 2004. Clathrin adaptor epsinR is required for retrograde sorting on early endosomal membranes. Dev Cell 6: $525-538$. 
Seaman MN. 2007. Identification of a novel conserved sorting motif required for retromer-mediated endosome-toTGN retrieval. J Cell Sci 120: 2378-2389.

Seaman MN. 2012. The retromer complex-Endosomal protein recycling and beyond. J Cell Sci 125: 4693-4702.

Seaman MN, Marcusson EG, Cereghino JL, Emr SD. 1997. Endosome to Golgi retrieval of the vacuolar protein sorting receptor, Vps10p, requires the function of the VPS29, VPS30, and VPS35 gene products. J Cell Biol 137: 79-92.

Seaman MN, McCaffery JM, Emr SD. 1998. A membrane coat complex essential for endosome-to-Golgi retrograde transport in yeast. J Cell Biol 142: 665-681.

Seaman MN, Harbour ME, Tattersall D, Read E, Bright N. 2009. Membrane recruitment of the cargo-selective retromer subcomplex is catalysed by the small GTPase Rab7 and inhibited by the Rab-GAP TBC1D5. J Cell Sci 122: 2371-2382.

Shi H, Rojas R, Bonifacino JS, Hurley JH. 2006. The retromer subunit Vps26 has an arrestin fold and binds Vps35 through its C-terminal domain. Nat Struct Mol Biol 13: 540-548.

Shiba Y, Römer W, Mardones GA, Burgos PV, Lamaze C, Johannes L. 2010. AGAP2 regulates retrograde transport between early endosomes and the TGN. J Cell Sci 123: 2381-2390.

Siegenthaler BM, Rajendran L. 2012. Retromers in Alzheimer's disease. Neurodegener Dis 10: 116-121.

Small SA, Kent K, Pierce A, Leung C, Kang MS, Okada H, Honig L, Vonsattel JP, Kim TW. 2005. Model-guided microarray implicates the retromer complex in Alzheimer's disease. Ann Neurol 58: 909-919.

Steinberg F, Gallon M, Winfield M, Thomas E, Bell AJ, Heesom KJ, Tavaré JM, Cullen PJ. 2013. A global analysis of SNX27-retromer assembly and cargo specificity reveals a function in glucose and metal ion transport. Nat Cell Biol 15: $461-471$.

Strochlic TI, Setty TG, Sitaram A, Burd CG. 2007. Grd19/ Snx3p functions as a cargo-specific adapter for retromerdependent endocytic recycling. J Cell Biol 177: 115-125.

Teis D, Saksena S, Judson BL, Emr SD. 2010. ESCRT-II coordinates the assembly of ESCRT-III filaments for cargo sorting and multivesicular body vesicle formation. EMBO J 29: 871-883.

Temkin P, Lauffer B, Jäger S, Cimermancic P, Krogan NJ, von Zastrow M. 2011. SNX27 mediates retromer tubule entry and endosome-to-plasma membrane trafficking of signalling receptors. Nat Cell Biol 13: 715-721.

van Kerkhof P, Lee J, McCormick L, Tetrault E, Lu W, Schoenfish M, Oorschot V, Strous GJ, Klumperman J, $\mathrm{Bu}$ G. 2005. Sorting nexin 17 facilitates LRP recycling in the early endosome. EMBO J 24: 2851-2861.

van Weering JR, Sessions RB, Traer CJ, Kloer DP, Bhatia VK, Stamou D, Carlsson SR, Hurley JH, Cullen PJ. 2012a. Molecular basis for SNX-BAR-mediated assembly of distinct endosomal sorting tubules. EMBO J31: 4466-4480. van Weering JR, Verkade P, Cullen PJ. 2012b. SNX-BARmediated endosome tubulation is co-ordinated with endosome maturation. Traffic 13: 94-107.

Vardarajan B, Bruesegem S, Harbour M, St George-Hyslop P, Seaman MNJ, Farrer LA. 2012. Identification of Alzheimer disease associated variants in genes that regulate retromer function. Neurobiol Aging 33: e15-e30.

Vergés M, Luton F, Gruber C, Tiemann F, Reinders LG, Huang L, Burlingame AL, Haft CR, Mostov KE. 2004. The mammalian retromer regulates transcytosis of the polymeric immunoglobulin receptor. Nat Cell Biol 6: $763-769$.

Vilariño-Güell C, Wider C, Ross OA, Dachsel JC, Kachergus JM, Lincoln SJ, Soto-Ortolaza AI, Cobb SA, Wilhoite GJ, Bacon JA, et al. 2011. VPS35 mutations in Parkinson disease. Am J Hum Genet 89: 162-167.

Wang D, Guo M, Liang Z, Fan J, Zhu Z, Zang J, Zhu Z, Li X, Teng M, Niu L, et al. 2005. Crystal structure of human vacuolar protein sorting protein 29 reveals a phosphodiesterase/nuclease-like fold and two protein-protein interaction sites. J Biol Chem 280: 22962-22967.

Wassmer T, Attar N, Bujny MV, Oakley J, Traer CJ, Cullen PJ. 2007. A loss-of-function screen reveals SNX5 and SNX6 as potential components of the mammalian retromer. $J$ Cell Sci 120: 45-54.

Wassmer T, Attar N, Harterink M, van Weering JR, Traer CJ, Oakley J, Goud B, Stephens DJ, Verkade P, Korswagen HC, et al. 2009. The retromer coat complex coordinates endosomal sorting and dynein-mediated transport, with carrier recognition by the trans-Golgi network. Dev Cell 17: $110-122$.

Wen L, Tang FL, Hong Y, Luo SW, Wang CL, He W, Shen C, Jung JU, Xiong F, Lee DH, et al. 2011. VPS35 haploinsufficiency increases Alzheimer's disease neuropathology. $J$ Cell Biol 195: 765-779.

Wollert T, Hurley JH. 2010. Molecular mechanism of multivesicular body biogenesis by ESCRT complexes. Nature 464: 864-869.

Yang PT, Lorenowicz MJ, Silhankova M, Coudreuse DY, Betist MC, Korswagen HC. 2008. Wnt signaling requires retromer-dependent recycling of MIG-14/Wntless in Wnt-producing cells. Dev Cell 14: 140-147.

Zelazny E, Santambrogio M, Pourcher M, Chambrier P, Berne-Dedieu A, Fobis-Loisy I, Miege C, Jaillais Y, Gaude T. 2013. Mechanisms governing the endosomal membrane recruitment of the core retromer in Arabidopsis. J Biol Chem 288: 8815-8825.

Zhang P, Wu Y, Belenkaya TY, Lin X. 2011. SNX3 controls Wingless/Wnt secretion through regulating retromerdependent recycling of Wntless. Cell Res 21: 1677-1690.

Zhou B, Wu Y, Lin X. 2011. Retromer regulates apical-basal polarity through recycling Crumbs. Dev Biol 360: 87-95.

Zimprich A, Benet-Pagès A, Struhal W, Graf E, Eck SH, Offman MN, Haubenberger D, Spielberger S, Schulte EC, Lichtner P, et al. 2011. A mutation in VPS35, encoding a subunit of the retromer complex, causes late-onset Parkinson disease. Am J Hum Genet 89: 168-175. 


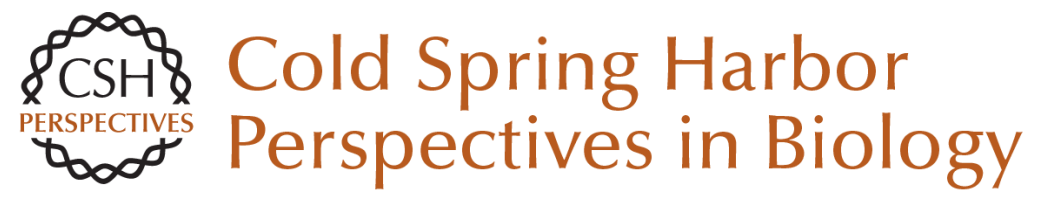

\section{Retromer: A Master Conductor of Endosome Sorting}

Christopher Burd and Peter J. Cullen

Cold Spring Harb Perspect Biol 2014; doi: 10.1101/cshperspect.a016774

Subject Collection Endocytosis

\section{Endocytosis: Past, Present, and Future} Sandra L. Schmid, Alexander Sorkin and Marino Zerial

Rab Proteins and the Compartmentalization of the Endosomal System

Angela Wandinger-Ness and Marino Zerial

Cargo Sorting in the Endocytic Pathway: A Key Regulator of Cell Polarity and Tissue Dynamics Suzanne Eaton and Fernando Martin-Belmonte

Unconventional Functions for Clathrin, ESCRTs, and Other Endocytic Regulators in the

Cytoskeleton, Cell Cycle, Nucleus, and Beyond:

Links to Human Disease

Frances M. Brodsky, R. Thomas Sosa, Joel A. Ybe, et al.

Endocytosis of Viruses and Bacteria Pascale Cossart and Ari Helenius

Lysosomal Adaptation: How the Lysosome Responds to External Cues Carmine Settembre and Andrea Ballabio

Reciprocal Regulation of Endocytosis and Metabolism

Costin N. Antonescu, Timothy E. McGraw and Amira Klip

Endocytosis and Autophagy: Exploitation or Cooperation?

Sharon A. Tooze, Adi Abada and Zvulun Elazar
Imaging and Modeling the Dynamics of

Clathrin-Mediated Endocytosis

Marcel Mettlen and Gaudenz Danuser

Endocytic Accessory Factors and Regulation of

Clathrin-Mediated Endocytosis

Christien J. Merrifield and Marko Kaksonen

The Complex Ultrastructure of the Endolysosomal

System Judith Klumperman and Graça Raposo

The Biogenesis of Lysosomes and

Lysosome-Related Organelles

J. Paul Luzio, Yvonne Hackmann, Nele M.G.

Dieckmann, et al.

Endocytosis, Signaling, and Beyond

Pier Paolo Di Fiore and Mark von Zastrow

Clathrin-Independent Pathways of Endocytosis Satyajit Mayor, Robert G. Parton and Julie G. Donaldson

The Role of Endocytosis during Morphogenetic Signaling Marcos Gonzalez-Gaitan and Frank Jülicher

Role of Endosomes and Lysosomes in Human Disease

Frederick R. Maxfield

For additional articles in this collection, see http://cshperspectives.cshlp.org/cgi/collection/

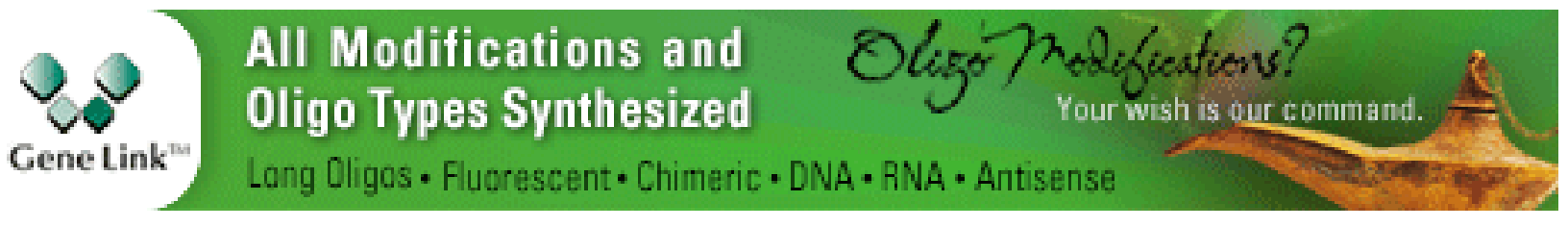


For additional articles in this collection, see http://cshperspectives.cshlp.org/cgi/collection/

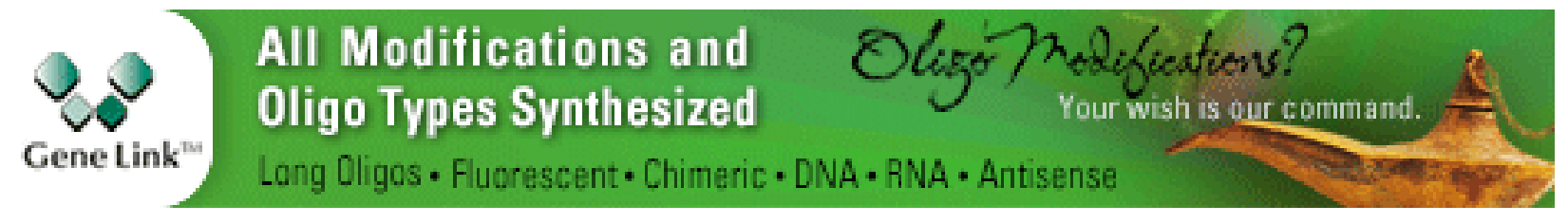

Copyright @ 2014 Cold Spring Harbor Laboratory Press; all rights reserved 